\title{
Hypertension and Micro-Vascular Complications Among Type 2 Dm Adult Patients in Mukalla, Yemen
}

\author{
Abdullah Salim Bin Ghouth ${ }^{1 *}$, Adnan Abdullah Ba-Karman², Hassan Ahmed Alaidroos ${ }^{3}$, Mohammed Hassan Alajely ${ }^{3}$, Mohsen Hussein \\ Bin-Talib3, Ruba Salem Bin-Jadnan ${ }^{3}$, Salem Farj Zanjy ${ }^{3}$, Shatha Khalid Bin-Abduat ${ }^{3}$ \\ ${ }^{1}$ Professor and head of community medicine department, Hadramout University College of Medicine, Mukalla (Yemen) \\ ${ }^{2}$ Assistant professor of clinical hematology. Department of Internal Medicine, Hadramout University College of Medicine, Mukalla (Yemen) \\ ${ }^{3}$ Students of Medical laboratory sciences, Hadramout University College of Medicine, Mukalla (Yemen)
}

*Corresponding author: Abdulla Salem Bin Ghouth, rofessor and head of community medicine department, Hadramout University College of Medicine, Mukalla (Yemen)

Received date: February 20, 2020; Accepted date: March 10, 2020; published date: March 16,2020

Citation: Abdullah Salim Bin Ghouth, Adnan Abdullah Ba-Karman, Hassan Ahmed Alaidroos, Mohammed Hassan Alajely, Mohsen Hussein BinTalib, Ruba Salem Bin-Jadnan, Salem Farj Zanjy, Shatha Khalid Bin-Abduat. Hypertension and Micro-Vascular Complications Among Type 2 Dm Adult Patients in Mukalla, Yemen. J Clinical Research and Reports, 3(5); DOI:10.31579/2690-1919/056

Copyright: (C) 2020 Abdullah Salim Bin Ghouth. This is an open access article distributed under the Creative Commons Attribution License, which permits unrestricted use, distribution, and reproduction in any medium, provided the original work is properly cited.

\begin{abstract}
The Background and Purpose: to assess the prevalence of hypertension and micro-vascular complications among type 2 diabetic patients registered in primary health care center in Mukalla city at eastern Yemen.

Methods: A Cross-sectional study was conducted in a randomly selected eligible patients from the diabetic registry of the AL Noor Charity Center (ACC), Mukalla city in Yemen.

Results: Prevalence of hypertension in the T2DM patients were 46.7\% (56/120). Retinopathy is the most micro-vascular complications among the adults having T2DM $(73 / 120,60.8 \%)$ while nephropathy is the least prevalence $(13 / 120,10.8 \%)$, prevalence of neuropathy was $49.2 \%$ (59/120). a high prevalence of retinopathy in males $(66 \%)$ than females $(55.7 \%)$ and a high prevalence of neuropathy in male adults $(52.2 \%)$ than females $(46 \%)$. No statistical significant difference were exit related to gender for any studied complications. Similar findings were observed regarding age related variations.

Conclusion: A high prevalence of hypertension, retinopathy and neuropathy were reported among T2DM patients in Mukalla. Adopting effective and safe treatment strategies are highly recommended to prevent premature death and complications due to DM.
\end{abstract}

Key words: Hypertension; micro vascular complications; DM

\section{Introduction}

Diabetes mellitus (DM) is a syndrome consisting of metabolic, vascular and neuropathic components that are interrelated. It is defined as group of metabolic disorder that is characterized by hyperglycemia resulting from defect in insulin secretion, insulin action or both, which leads to alteration in carbohydrate, fat and protein metabolism.[1]

Type 2 diabetes is estimated to affect over 150 million people worldwide. 2 This prevalence is increasing rapidly, partly through changes in case ascertainment and diagnostic criteria, but mainly through lifestyle changes in countries which know a fast development. 2 Type 2 diabetes is also associated with an increased risk of premature death due to cardiovascular disease (CVD), stroke, and renal disease. 3 Hypertension is a major risk factor for cardiovascular disease, stroke and ischemic heart disease. Therefore, this factor represents one of the most preventable causes of morbidity and premature mortality in developed as well as developing countries.4 Hypertension and diabetes frequently coexist. The frequency of hypertension in diabetic population is almost twice as compared to non-diabetic general population.5 There is a considerable evidence for an increased prevalence of hypertension in diabetic persons6 The prevalence rate of hypertension among type 2 diabetics is higher than that of age and sex-matched patients without diabetes, ranging between $32 \%$ and $82 \% .7-12$ The coexistence of hypertension and type 2 diabetes is a major contributor to the development and progression of macro- vascular and micro-vascular complications in people with diabetes compared to the general population.4, 13-15 As an example of this problem in developing countries; The prevalence of hypertension, the frequencies of undiagnosed hypertension and uncontrolled hypertension among Moroccan patients with type 2 diabetes were very high. 16

Micro-vascular complications from type 2 diabetes are common and include retinopathy leading to various degrees of visual impairment including blindness and has become a major cause of blindness throughout the world; 17,18 neuropathy, leading to pain and numbness, chronic and recurrent infected ulcers in the extremities which can lead to amputation; and nephropathy characterized by proteinuria ultimately leading to end stage renal disease. It constitutes the major work load of dialysis centers.3,7 Micro-vascular complications are the major outcome of type 2 Diabetes Mellitus progression, and increase diabetic mortality. 19

Information on prevalence of type 2 diabetes mellitus related complications is important for the updating of policies and practices in diabetic care management to gain better control of type 2 diabetes mellitus. In Yemen the epidemiology of diabetes mellitus remains poor, and there is little information available on this issue in the international literature. 20

The aims of this study were to assess the prevalence of hypertension and micro-vascular complications among type 2 diabetic patients registered in in primary health care center in Mukalla city at eastern Yemen. 


\section{Patients and methods:}

All adults (both males and females) at age of $>40$ years, who receiving care in Al-Noor charity center (ACC) during the period from May-July 2017 constituted the study population for purpose of this work. A sample size of 120 eligible patients was statistically calculated based on an expected proportion of $34.29 \% 21$.

The Inclusion criteria were determined as all medically diagnosed T2DM patients above 40 years of age of both sex (male and female) who registered on diabetic treatment schedule and visited ACC at regular intervals) while patients who already taking lipid-lowering drugs and pregnant women were excluded.

ACC is a primary health care center and it is a community based services center of NGO in Mukalla city at eastern Yemen. It is the only center in Mukalla establishing diabetic registry and clinic ten years ago.

A Cross-sectional study was conducted in a randomly selected eligible patients from the diabetic registry of the AL Noor Charity Center (ACC), Mukalla city in Yemen during the period from May-July 2017

A well structured questionnaire was the tool for data collection from patients. The questionnaire include personal data, family history, history of the illness. Samples of blood were collected from patients by well trained 4th medical laboratory students in Hadramout University. .

All the obtained data are fed on computer using the statistical package of social sciences version (SPSS version 23 ). Statistical methods used for univariate analysis are mean, median, standard deviation, range and interquartile range, for bivariate analysis, independent t- test for difference between two sample means, chi square test for association between categorical variables. A cut-off point of 0.05 was determined for significance level

\section{Results:}

The mean age of participants was 54.8[1]years $( \pm 9.33)$. Out of 120 diabetic patients enrolled in the study, 6[1]were females (50.8\%), $52.4 \%$ were unemployed, $30 \%$ were illiterates, $35.8 \%$ were overweight and $25 \%$ were obese. (Table 1).

Prevalence of hypertension in the T2DM patients were $46.7 \%$ (56/120). Retinopathy is the most micro-vascular complications among the adults having T2DM $(73 / 120,60.8 \%)$ while nephropathy is the least prevalence $(13 / 120,10.8 \%)$, prevalence of neuropathy was $49.2 \%$ (59/120). (Figure 1)

\begin{tabular}{|c|c|c|c|}
\hline \multirow{2}{*}{\multicolumn{2}{|c|}{ Characteristics }} & Frequency & Percentage \% \\
\hline \multirow{3}{*}{ Age } & $41-50$ years & 47 & 39.2 \\
\cline { 2 - 4 } Gender & $51-60$ years & 43 & 35.8 \\
\cline { 2 - 4 } & $>60$ years & 30 & 25 \\
\cline { 2 - 4 } & Male & 59 & 59.2 \\
\cline { 2 - 4 } & Female & 61 & 24.2 \\
\hline \multirow{3}{*}{ Occupation } & Government & 29 & 23.4 \\
\cline { 2 - 4 } & Private work & 63 & 52.4 \\
\cline { 2 - 4 } & unemployed & 36 & 30.0 \\
\cline { 2 - 4 } & Illiterate & 26 & 21.7 \\
\cline { 2 - 4 } & Read and write & 33 & 27.5 \\
\cline { 2 - 4 } & Primary & 14 & 11.7 \\
\cline { 2 - 4 } & Secondary & 11 & 9.1 \\
\hline
\end{tabular}

Table 1: Demographic characteristics the studied Type 2 diabetic patients attending AL Noor Charity Clinic (ACC), Mukalla city, 2017.

Figure 1. Prevalence of hypertension, retinopathy, neuropathy and nephropathy among T2DM patients, Mukalla, 2018

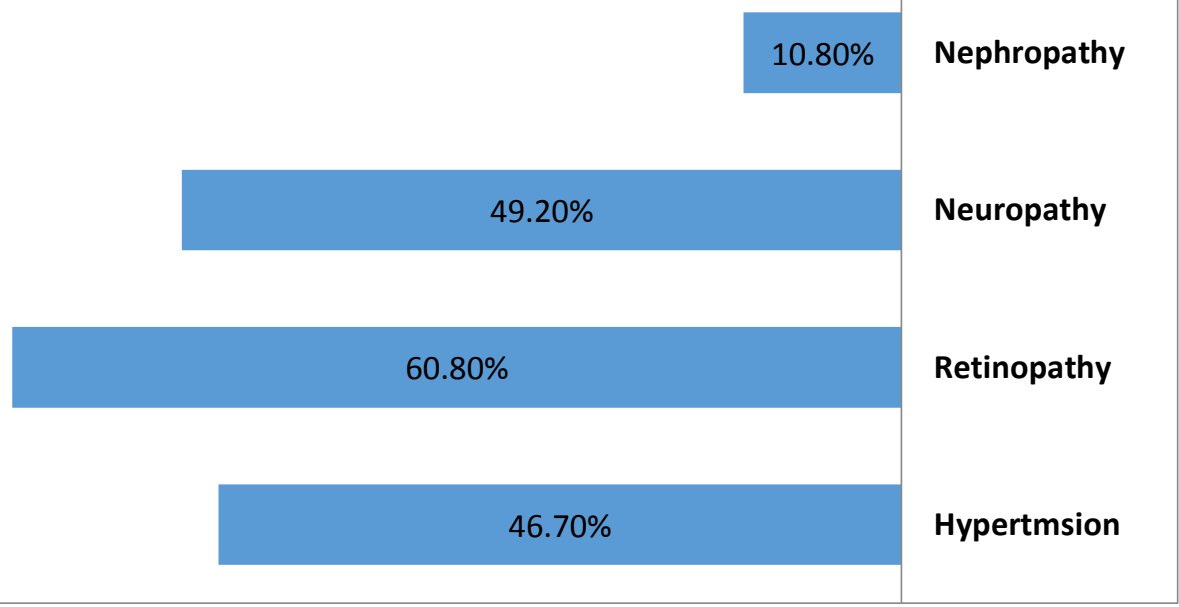


Prevalence of hypertension in male T2DM adults was $45.5 \%$ in males while in females was $47.5 \%$. a high prevalence of retinopathy in males $(66 \%)$ than females $(55.7 \%)$ and a high prevalence of neuropathy in male adults $(52.2 \%)$ than females $(46 \%)$, low prevalence of nephropathy were observed in both males $(13.5 \%$ ( and females $(8 \%)$. No statistical significant difference were exit related to gender for any studied complications of T2DM among adults.

\begin{tabular}{|l|ll|lll|l|}
\hline \multicolumn{1}{|c|}{ Complications } & \multicolumn{2}{|c|}{$\begin{array}{c}\text { Male (n= 59) } \\
\text { No }\end{array}$} & \multicolumn{2}{c|}{$\begin{array}{c}\text { Female (n=61) } \\
\text { Prevalence\% }\end{array}$} & \multicolumn{2}{c|}{ P-value } \\
\hline Hypertension & 27 & $(45.7 \%)$ & 29 & $(47.5 \%)$ & 0.496 \\
\hline Retinopathy & 39 & $(66 \%)$ & 34 & $(55.7 \%)$ & 0.165 \\
\hline Neuropathy & $3[1]$ & $(52.5 \%)$ & 28 & $(46 \%)$ & 0.293 \\
\hline Nephropathy & 8 & $(13.5 \%)$ & 5 & $(8 \%)$ & 0.258 \\
\hline
\end{tabular}

Table 2. Gender specific prevalence rates of hypertension and micro-vascular complication of T2DM among diabetic adults, Mukalla, 2018

The median age is used foe classification of age groups into two groups ( $\leq 58$ years and $>58$ years). Prevalence of hypertension, retinopathy and neuropathy were more among age groups 49 to 58 years than age group above 58 years while nephropathy was common in age group of $30-58$ years, but the difference is not statistically significant. (Table. 3 )

\begin{tabular}{|l|lll|ll|l|}
\hline Complications & \multicolumn{2}{|l|}{$\leq 58$ years $(\mathrm{n}=77)$} & \multicolumn{2}{|l|}{$>58$ years $(\mathrm{n}=43)$} & P-value \\
& No & Prevalence\% & No & Prevalence\% & \\
\hline Hypertension & 37 & $(48 \%)$ & 19 & $(44 \%)$ & 0.415 \\
\hline Retinopathy & 49 & $(63.6 \%)$ & 24 & $(55.8 \%)$ & 0.258 \\
\hline Neuropathy & $4[1]$ & $(53.2 \%)$ & 18 & $(41.8 \%)$ & 0.157 \\
\hline Nephropathy & 6 & $(7.8 \%)$ & 7 & $(14.5 \%)$ & 0.130 \\
\hline
\end{tabular}

Table 3. Gender specific prevalence rates of hypertension and micro-vascular complication of T2DM among diabetic adults, Mukalla, 2018

\section{Discussion}

This study highlight on the magnitude of hypertension and micro-vascular complications among T2DM in Yemen. A high prevalence of hypertension, retinopathy and neuropathy were reported and low prevalence of nephropathy, there was no significance difference exist regarding age and gender. Patients with diabetes mellitus (DM) are at risk of adverse cardiovascular (CV) outcomes, including micro-vascular and atherosclerotic complications. 22

Type 2 diabetes mellitus (T2DM) is a global pandemic and its prevalence is rapidly increasing in developing countries, including Yemen. The most common co-morbidity associated with T2DM is hypertension. In Thailand; the most common co-morbidity of T2DM is hypertension.23 T2DM with a hypertension co-morbidity is likely to exacerbate the development of, or more severe micro-vascular complications.

The prevalence of hypertension among T2DM patients varies across countries and is reported to range from $20.6 \%$ to $78.4 \%$ in the Southeast Asian region, and $9.7 \%$ to $70.4 \%$ in the African region2[1]The problem is not limited to the developing countries only, Type 2 diabetes mellitus (T2DM) and hypertension (HT) are major non-communicable health problems in both developing and developed countries. 24

Micro-vascular complications among T2DM patients are a consequence of prolonged hyperglycemia, 23 and these complications include diabetic neuropathy, diabetic nephropathy and diabetic retinopathy. The prevalence of micro-vascular complications among T2DM patients is high, but has been shown to vary widely across populations.26-28 In this study a high prevalence of retinopathy and neuropathy were reported in comparing with other studies in China, Australia and India. A study in China reported prevalence of neuropathy, nephropathy, ocular lesions, and foot disease among T2DM patients to be $17.8 \%, 10.7 \%, 14.8 \%$, and $0.8 \%$, respectively.30 Another study in Australia reported the prevalence of diabetic retinopathy among T2DM patients is 21.9\%.3[1] Prevalence of any micro-vascular in newly diagnosed T2DM in India is $30.2 \% .27$ It was reported elsewhere about the importance of controlling BP among $\mathrm{T} 2 \mathrm{DM}$ to prevent further micro and macro-vascular complications. Hurst
C et al in 2015 indicate in their study in Thailand that hypertension was highly associated with micro-vascular complications, and blood pressure control is highly important in terms of preventing micro-vascular complication among patients with T2DM.23 Moreover and based on available evidence, patients with DM and persistent BP readings $>140 / 90$ $\mathrm{mmHg}$ should be started on antihypertensive drug therapy.32,33 These data are clear that drug therapy in hypertensive DM patients is effective in reducing mortality; preventing adverse CV events, such as myocardial infarction, stroke, and heart failure; and slowing the progression of existing kidney disease.34,35 It is important to keep in mind that the degree of BP reduction is the major determinant of reduction in CV risk, superseding the choice of antihypertensive drug; a dictum that is valid in patients with DM.36

\section{Conclusion:}

A high prevalence of hypertension, retinopathy and neuropathy were reported among T2DM patients in Mukalla. Adopting effective and safe treatment strategies are highly recommended to prevent premature death and complications due to DM.

\section{References}

1. Gavin JR. Report of the expert committee on the diagnosis and classification of diabetes mellitus. Diabetes Care, (1998); 21(1): 5-519.

2. King H, Aubert RE, Herman WH. Global burden of diabetes, 1995-2025: prevalence, numerical estimates, and projections. Diabetes Care. 1998 Sep;21(9):1414-31.

3. Genuth S. A case for blood glucose control. Advances in internal medicine. 1995;40:573-623.

4. Libby P, Nathan DM, Abraham K, Brunzell JD. Report of the National Heart, Lung and Blood Institute: National Institute of Diabetes and Digestive and Kidney Diseases Working Group on 
Cardiovascular Complications of DM. Circulation. 2005;111:3489-93.

5. Paul B, Sapra B, Maheswari S, Goyal RK. Role of Losartan therapy in the management of diabetic hypertension. The Journal of the Association of Physicians of India. 2000;48:514-7.

6. National High Blood Pressure Education Program Working Group report on hypertension in diabetes. Hypertension. 1994 Feb;23(2):145-58.

7. Satman I, Yilmaz T. Population-based study of diabetes and risk characteristics in Turkey. Diabetes Care. 2002;25:1551-6.

8. Tseng $\mathrm{CH}$. Higher risk of hypertension in indigenous type 2 diabetic patients in Taiwan. Journal of Hypertension. 2006;24(9):1817-21.

9. Baskar V, Kamalakannan D, Holland MR, Singh BM. The prevalence of hypertension and utilization of antihypertensive therapy in a district Diabettes Population. Diabetes Care. 2002;25:2107-8.

10. Comaschi M, Coscelli C, Cucinotta D, Malini P, Manzato E, Nicolucci A. SFIDA Study Group-Italian Association of Diabetologists (AMD). Cardiovascular risk factors and metabolic control in type 2 diabetic subjects attending outpatient clinics in Italy: the SFIDA (survey of risk factors in Italian diabetic subjects by AMD) study. Nutr Metab Cardiovasc Dis. 2005 Jun;15(3):204-11.

11. Del Cañizo-Gómez FJ, Moreira-Andrés MN. Cardiovascular risk factors in patients with type 2 diabetes. Do we follow the guidelines? Diabetes Res Clin Pract. 2004 Aug;65(2):125-33.

12. Baskar V, Kamalakannan D, Holland MR, Singh BM. Does ethnic origin have an independent impact on hypertension and diabetic complications? Diabetes Obes Metab. 2006 Mar;8(2):214-9.

13. Fong DS, Aiello LP, Ferris FL, Klein R. Diabbetic retinopathy. Diabetes Care. 2004;27:2540-53.

14. Tesfaye S, Chaturvedi N, Eaton SE, Ward JD, Manes C, IonescuTirgoviste C, Witte DR, Fuller JH. EURODIAB Prospective Complications Study Group. Vascular risk factors and diabetic neuropathy. N Engl J Med. 2005 Jan 27;352(4):341-50.

15. Sowers JR, Williams M, Epstein M, Bakris G. Hypertension in patients with diabetes: strategies for drug therapy to reduce complications. Postgraduate medicine. 2000;107:47-54.

16. Berraho M, El Achhab Y, Benslimane A, EL Rhazi K, Chikri M, Nejjari C. Hypertension and type 2 diabetes: a cross-sectional study in Morocco (EPIDIAM Study). The Pan African Medical Journal. 2012;11:52.

17. Atlas, 2nd Edition . Grand, Ed. Belgium: Brussels; 2003. International diabetes Federation Diabetes.

18. Turner RC, Holman RR. Lessons from UKPDS Diabetes. Res Clin Pract. 1995;28(Suppl 7):S151-157.

19. Ahmedani MY, Hydrie MZ, Iqbal A, Gul A, Mirza WB, Basit A. Prevalence of microalbuminuria in type 2 diabetic patients in Karachi: Pakistan: a multi-center study. J Pak Med Assoc. 2005;55(9):382-386.

20. (A.A. Gunaid[1] and A.M. Assabri2 Prevalence of type 2 diabetes and other cardiovascular risk factors in a semirural area in Yemen. Eastern Mediterranean Health Journal, Vol. 14, No. 1, 2008)

21. Prevalence of dyslipidemia in patients with type 2 diabetes mellitus : a hospital based study in Kishanganj, India. Int J Res Med Sci (2015);3: 3691-7

22. Rizvi AA. ADDRESSING HYPERTENSION IN THE PATIENT WITH TYPE 2 DIABETES MELLITUS: PATHOGENESIS, GOALS, AND THERAPEUTIC APPROACH. European medical journal Diabetes. 2017;5(1):84-92.)
23. Mohan V, Seedat YK, Pradeepa R. The rising burden of diabetes and hypertension in southeast asian and african regions: need for effective strategies for prevention and control in primary health care settings. Int J Hypertens. 2013;2013:409083.

24. Apidechkul T. Prevalence and factors associated with type 2 diabetes mellitus and hypertension among the hill tribe elderly populations in northern Thailand. BMC Public Health. 2018 Jun 5;18(1):694. doi: 10.1186/s12889-018-5607-2.

25. Holt RI. Textbook of diabetes. 4th ed. Chichester: WileyBlackwell; 2010. Chapter 36, Pathogenesis of microvascular complications; pp. 553-574.

26. Del Canizo Gomez FJ, Fernandez Perez C, Moreno Ruiz I, de Gorospe Perez-Jauregui C, Silveira Rodriguez B, Gonzalez Losada T, Segura Galindo A. Microvascular complications and risk factors in patients with type 2 diabetes. Endocrinol Nutr. 2011;58:163-168.

27. Raman R, Gupta A, Krishna S, Kulothungan V, Sharma T. Prevalence and risk factors for diabetic microvascular complications in newly diagnosed type II diabetes mellitus. Sankara Nethralaya Diabetic Retinopathy Epidemiology and Molecular Genetic Study (SN-DREAMS, report. J Diabetes Complications. 2012;26:123-128.

28. Amini M, Parvaresh E. Prevalence of macro- and microvascular complications among patients with type 2 diabetes in Iran: a systematic review. Diabetes Res Clin Pract. 2009;83:18-25.

29. Leelawattana R, Pratipanawatr T, Bunnag P, Kosachunhanun N, Suwanwalaikorn S, Krittiyawong S, Chetthakul T, Plengvidhya N, Benjasuratwong $\mathrm{Y}$, Deerochanawong $\mathrm{C}$, Mongkolsomlit S, Ngarmukos C, Rawdaree P. Thailand diabetes registry project: prevalence of vascular complications in long-standing type 2 diabetes. J Med Assoc Thai. 2006;89(Suppl 1):S54-S59.

30. Liu Z, Fu C, Wang W, Xu B. Prevalence of chronic complications of type 2 diabetes mellitus in outpatients: a cross-sectional hospital based survey in urban China. Health Qual Life Outcomes. 2010;8:62.

31. Tapp RJ, Shaw JE, Harper CA, de Courten MP, Balkau B, McCarty DJ, Taylor HR, Welborn TA, Zimmet PZ AusDiab Study Group. The prevalence of and factors associated with diabetic retinopathy in the Australian population. Diabetes Care. 2003;26:1731-1737.

32. James PA, et al. 2014 evidence-based guideline for the management of high blood pressure in adults: Report from the panel members appointed to the Eighth Joint National Committee (JNC 8) JAMA. 2014;311(5):507-20.

33. Mancia G, et al. 2013 ESH/ESC Guidelines for the management of arterial hypertension: The Task Force for the management of arterial hypertension of the European Society of Hypertension (ESH) and of the European Society of Cardiology (ESC) J Hypertens. 2013;31(7):1281-357.

34. Vijan S, Hayward RA. Treatment of hypertension in type 2 diabetes mellitus: Blood pressure goals, choice of agents, and setting priorities in diabetes care. Ann Intern Med. 2003;138(7):593-602.

35. Snow V, et al. Clinical Efficacy Assessment Subcommittee of the American College of Physicians. The evidence base for tight blood pressure control in the management of type 2 diabetes mellitus. Ann Intern Med. 2003;138(7):587-92.

36. Tight blood pressure control and risk of macrovascular and microvascular complications in type 2 diabetes: UKPDS 38 . UK Prospective Diabetes Study Group. BMJ. 1998;317(7160):70313. 